\title{
Predicting the availability of production lines by combining simulation and surrogate model
}

\author{
Jia, Y. ${ }^{a}$, Tian, H. ${ }^{a}$, Chen, C. ${ }^{a,}{ }^{*}$, Wang, L. ${ }^{a, b}$ \\ ${ }^{a}$ School of Mechanical Science and Engineering, Jilin University, Changchun, P.R. China \\ ${ }^{b}$ School of Mechanical Engineering, Dalian University of Technology, Dalian, P.R. China
}

\begin{abstract}
A B S T R A C T
The availability analysis plays a significant part in both the design and operations management of production lines. In this paper, a method combining discrete event simulation (DES) and surrogate model is presented to predict the availability of production lines with unreliable workstations and finite intermediate buffers. The DES can conduct computer experiments for production lines with the help of design of experiments (DOE) under the Matlab environment. The surrogate model is constructed by using Kriging model integrated with Latin hypercube sampling (LHS), which can predict the responses based on a limited set of simulation results. The major advantages of the proposed approach are its flexibility and convenience. Also, it is the first time to investigate Kriging opportunities in predicting the performance of production lines. Finally, an application in a crankshaft production line is presented, and the results indicate that the proposed approach can achieve higher prediction accuracy than the other methods.
\end{abstract}

(c) 2017 PEI, University of Maribor. All rights reserved.

\author{
ARTICLE INFO \\ Keywords: \\ Production lines \\ Availability prediction \\ Discrete event simulation (DES) \\ Kriging model \\ Latin hypercube sampling (LHS) \\ *Corresponding author: \\ cchchina@jlu.edu.cn \\ (Chen, C.)
}

Article history:

Received 5 May 2017

Revised 22 June 2017

Accepted 10 July 2017

\section{References}

[1] Lv, Y., Zhang, J., Qin, W. (2017). A genetic regulatory network-based sequencing method for mixed-model assembly lines, Advances in Production Engineering \& Management, Vol. 12, No. 1, 62-74, doi: 10.14743/apem2017.1. 240.

[2] Govil, M.K., Fu, M.C. (1999). Queueing theory in manufacturing: A survey, Journal of Manufacturing Systems, Vol. 18, No. 3, 214-240, doi: 10.1016/S0278-6125(99)80033-8.

[3] Dallery, Y., Gershwin, S.B. (1992). Manufacturing flow line systems: A review of models and analytical results, Queueing Systems, Vol. 12, No. 1-2, 3-94, doi: 10.1007/BF01158636.

[4] Gershwin, S.B. (1987). An efficient decomposition method for the approximate evaluation of tandem queues with finite storage space and blocking, Operations Research, Vol. 35, No. 2, 291-305, doi: 10.1287/opre.35.2.291.

[5] Dallery, Y., David, R., Xie, X.-L. (1988). An efficient algorithm for analysis of transfer lines with unreliable machines and finite buffers, IIE Transactions, Vol. 20, No. 3, 280-283, doi: 10.1080/07408178808966181.

[6] Burman, M.H. (1995). New results in flow line analysis, PhD Thesis, Operations Research Center, Massachusetts Institute of Technology, USA.

[7] Xia, B., Xi, L., Zhou, B. (2012). An improved decomposition method for evaluating the performance of transfer lines with unreliable machines and finite buffers, International Journal of Production Research, Vol. 50, No. 15, 4009-4024, doi: 10.1080/00207543.2011.587842.

[8] Xia, B., Xi, L., Zhou, B., Du, S. (2013). An efficient analytical method for performance evaluation of transfer lines with unreliable machines and finite transfer-delay buffers, International Journal of Production Research, Vol. 51, No. 6, 1799-1819, doi: 10.1080/00207543.2012.713137.

[9] Colledani, M., Gershwin, S.B. (2013). A decomposition method for approximate evaluation of continuous flow multi-stage lines with general Markovian machines, Annals of Operations Research, Vol. 209, No. 1, 5-40, doi: 10.1007/s10479-011-0961-9. 
[10] Li, J., Blumenfeld, D.E., Huang, N., Alden, J.M. (2009). Throughput analysis of production systems: Recent advances and future topics, International Journal of Production Research, Vol. 47, No. 14, 3823-3851, doi: 10.1080/ 00207540701829752.

[11] Li, J., Meerkov, S.M. (2009). Production Systems Engineering, Springer, New York, USA, doi: 10.1007/978-0-38775579-3.

[12] Kuhn, W. (2006). Digital factory - Simulation enhancing the product and production engineering process, In: Proceedings of the 2006 Winter Simulation Conference, Monterey, USA, 1899-1906.

[13] Betterton, C.E., Cox, J.F. (2012). Production rate of synchronous transfer lines using Monte Carlo simulation, International Journal of Production Research, Vol. 50, No. 24, 7256-7270, doi: 10.1080/0207543.2011.645081.

[14] Dhouib, K., Gharbi, A., Ayed, S. (2009). Simulation based throughput assessment of non-homogeneous transfer lines, International Journal of Simulation Modelling, Vol. 8, No. 1, 5-15, doi: 10.2507/IJSIMM08(1)1.111.

[15] Dhouib, K., Gharbi, A., Ayed, S. (2008). Availability and throughput of unreliable, unbuffered production lines with non-homogeneous deterministic processing times, International Journal of Production Research, Vol. 46, No. 20, 5651-5677, doi: 10.1080/00207540701294635.

[16] Padhi, S.S., Wagner, S.M., Niranjan, T.T., Aggarwal, V. (2013). A simulation-based methodology to analyse production line disruptions, International Journal of Production Research, Vol. 51, No. 6, 1885-1897, doi: 10.1080/ 00207543.2012.720389.

[17] Heshmat, M., El-Sharief, M.A., El-Sebaie, M.G. (2013). Simulation modeling of automatic production lines with intermediate buffers, Journal of Engineering Sciences, Vol. 41, No. 6, 2175-2189.

[18] Supsomboon, S., Hongthanapach, K. (2014). A simulation model for machine efficiency improvement using reliability centered maintenance: case study of semiconductor factory, Modelling and Simulation in Engineering, Vol. 2014, 1-9, doi: 10.1155/2014/956182.

[19] Law, A.M. (2015). Simulation modeling and analysis, $5^{\text {th }}$ edition, McGraw-Hill, New York, USA.

[20] Macchi, M., Kristjanpoller, F., Garetti, M., Arata, A., Fumagalli, L. (2012). Introducing buffer inventories in the RBD analysis of process production systems, Reliability Engineering \& System Safety, Vol. 104, 84-95, doi: 10.1016/ j.ress.2012.03.015.

[21] Montgomery, D.C. (2013). Design and analysis of experiments, $8^{\text {th }}$ edition, Wiley, New Jersey, USA.

[22] Barton, R.R. (2013). Designing simulation experiments, In: Proceedings of the 2013 Winter Simulation Conference, Washington, USA, 342-353, doi: 10.1109/WSC.2013.6721432.

[23] Kleijnen, J.P.C. (2015). Design and analysis of simulation experiments, $2^{\text {nd }}$ edition, Springer International Publishing, Switzerland, doi: 10.1007/978-3-319-18087-8.

[24] Kleijnen, J.P.C. (2009). Kriging metamodeling in simulation: A review, European Journal of Operational Research, Vol. 192, No. 3, 707-716, doi: 10.1016/i.ejor.2007.10.013.

[25] Matta, A., Pezzoni, M., Semeraro, Q. (2012). A Kriging-based algorithm to optimize production systems approximated by analytical models, Journal of Intelligent Manufacturing, Vol. 23, No. 3, 587-597, doi: 10.1007/ s10845-010-0397-0.

[26] Lophaven, S.N., Nielsen, H.B., Søndergaard, J. (2002). DACE: A Matlab Kriging toolbox, Version 2.0, Informatics and Mathematical Modelling, Technical University of Denmark, Lyngby, Denmark.

[27] Jia, J. Moving Least Square(MLS2D), from http://cn.mathworks.com/matlabcentral/fileexchange/34547-movingleast-square-mIs2d-, accessed January12, 2012.

[28] Jia, Y., Yang, Z., Li, G., Du, X., He, J., Wang, L., Li, Q. (2016). An efficient semi-analytical simulation for availability evaluation of discrete production lines with unreliable machines, In: 2016 International Conference on System Reliability and Science, Paris, France, 115-121, doi: 10.1109/ICSRS.2016.7815849. 


\section{APEM}

\title{
Napovedovanje razpoložljivosti proizvodnih linij z združitvijo simulacije in nadomestnega modela
}

\author{
Jia, Y. ${ }^{a}$, Tian, H. ${ }^{a}$, Chen, C. ${ }^{a,}{ }^{*}$, Wang, L. ${ }^{a, b}$ \\ ${ }^{a}$ School of Mechanical Science and Engineering, Jilin University, Changchun, P.R. China \\ ${ }^{\mathrm{b}}$ School of Mechanical Engineering, Dalian University of Technology, Dalian, P.R. China
}

\section{POVZETEK}

Analiza razpoložljivosti igra pomembno vlogo pri načrtovanju in upravljanju proizvodnih linij. V tem prispevku je za predvidevanje razpoložljivosti proizvodnih linij z nezanesljivimi delovnimi postajami in končnim številom vmesnih skladišč predlagana metoda, ki združuje simulacijo diskretnega dogodka (DES) in nadomestni model. DES v programskem okolju Matlab omogoča izvedbo eksperimentov proizvodnih linij s pomočjo načrtovanja eksperimentov (DOE). Nadomestni model je zgrajen z uporabo Krigingovega modela $\mathrm{z}$ integracijo latinskega hiperkubičnega vzorčenja (LHS) in nudi rešitve na podlagi omejenega nabora simulacijskih rezultatov. Glavni prednosti predlaganega pristopa sta prilagodljivost in priročnost. Prav tako je prvič uporabljen Krigingov model pri napovedovanju uspešnosti proizvodnih linij. Nak koncu je predstavljena še aplikacija modela v proizvodni liniji za izdelavo ročične gredi. Rezultati so kazali, da lahko s predlaganim pristopom dosežemo višjo natančnost napovedi kot $\mathrm{z}$ drugimi metodami.

(C) 2017 PEI, University of Maribor. All rights reserved.

\section{PODATKI O ČLANKU}

Ključne besede:

Proizvodne linije

Napoved razpoložljivosti

Simulacija diskretnega dogodka

(DES)

Krigingov model

Latinsko hiperkubično vzorčenje (LHS)

*Kontaktna oseba: cchchina@jlu.edu.cn

(Chen, C.)

Zgodovina članka:

Prejet 5. maja 2017

Popravljen 22. junija 2017

Sprejet 10. julija 2017 